\title{
Protective effects of the antioxidant extract collected from Styela clava tunics on UV radiation-induced skin aging in hairless mice
}

\author{
EUN KYOUNG KOH ${ }^{1}$, JI EUN KIM ${ }^{1}$, JUN GO ${ }^{1}$, SUNG HWA SONG ${ }^{1}$, JI EUN SUNG ${ }^{1}$, HONG JOO SON ${ }^{1}$, \\ YOUNG JIN JUNG ${ }^{1}$, BAE HWAN KIM ${ }^{2}$, YOUNG SUK JUNG ${ }^{3}$ and DAE YOUN HWANG ${ }^{1}$ \\ ${ }^{1}$ Department of Biomaterials Science, College of Natural Resources and Life Science/Life and \\ Industry Convergence Research Institute, Pusan National University, Miryang, Gyeongsangnam-do 50463; \\ ${ }^{2}$ Department of Public Health, Keimyung University, Daegu 42601; \\ ${ }^{3}$ College of Pharmacy, Pusan National University, Busan 46241, Republic of Korea
}

Received June 8, 2015; Accepted August 19, 2016

DOI: $10.3892 / \mathrm{ijmm} .2016 .2740$

\begin{abstract}
Ultraviolet (UV) radiation is considered a primary cause of skin damage, which is characterized by deep wrinkles, roughness, laxity and pigmentation through oxidative stress and oxidative photodamage. To examine the therapeutic effects of ethanol extract of Styela clava tunics (EtSCT) on UV radiation-induced skin aging in hairless mice, alterations in skin phenotype, histological structures, inflammation, endoplasmic reticulum (ER) stress, oxidative conditions and toxicity were investigated during 13 weeks of UV irradiation and topical application of EtSCT. EtSCT showed high reducing power (3.1\%), 2,2-diphenyl-1-picrylhydrazyl (DPPH) radical scavenging activity (92.7\%) and NO scavenging activity $(15.6 \%)$ due to its high total flavonoids $(15.3 \mathrm{mg} / \mathrm{ml})$ and total phenolics $(36.8 \mathrm{mg} / \mathrm{ml})$. The topical application of EtSCT suppressed photoaging of the skin of UV-irradiated mice, and this was demonstrated by the inhibition of wrinkle formation, the suppression of the erythema index as well as the prevention of transepidermal water loss. Additionally, the epidermal thickness and adipocytes number were recovered to a similar level as that in the no radiation group in the UV + EtSCT-treated groups compared with the UV + vehicle-treated group, and the expression of collagen I increased. The attenuation of mitogen-activated protein kinase and ER stress signaling pathways activated by reactive oxygen species was also detected in the UV + EtSCT-treated group. Inflammatory responses including the infiltration of mast cells, CD31 expression
\end{abstract}

Correspondence to: Professor Dae Youn Hwang, Department of Biomaterials Science, College of Natural Resources and Life Science/Life and Industry Convergence Research Institute, Pusan National University, 50 Cheonghak-ri, Samnangjin-eup, Miryang, Gyeongsangnam-do 50463, Republic of Korea

E-mail: dyhwang@pusan.ac.kr

Key words: skin aging, antioxidant, ultraviolet radiation, Styela clava tunics, inflammation and interleukin-6 secretion were significantly lower in the $\mathrm{UV}+$ EtSCT-treated groups. Moreover, the concentration of malondialdehyde was reduced and the activity of superoxide dismutase was effectively recovered in the UV + EtSCT-treated groups compared with that in the vehicle-treated groups. Liver and kidney toxicity factors were maintained at a constant level. These results suggest that EtSCT has the potential for use as therapeutic drug which protects against skin aging by regulating the skin morphology, histopathological structures, ER stress, inflammation and oxidative conditions.

\section{Introduction}

Styela clava (SC), of the class Ascidiacea (ascidians or sea squirts) is a solitary, oviparous, hermaphrodite tunicate characterized by a rough and wrinkled brown surface and a club-shaped body (1). SC is found in East Asia, Australia, New Zealand, North America and Europe (2-4). The annual production of SC in suspended culture increased to 2,759 MT in 2013 owing to demand for use as a raw material in food production in Korea $(5,6)$. However, increasing SC consumption has resulted in rising levels of SC tunic (SCT), which is regarded as waste, and may cause environmental pollution $(7,8)$. Thus, many studies have been conducted to evaluate the possibility of using novel bioactive materials derived from SCT to provide solutions to this problem.

Natural polymers and bioactive compounds derived from SCT have been extensively applied for the treatment of inflammation, oxidative stress and surgical wounds. Cellulose complex derived from SCT exerted significant therapeutic effects on surgical wounds and bone defects in animals. Cellulose films (CF) have been successfully prepared from solutions of SCT cellulose powder completely dissolved in N-methylmorpholine$\mathrm{N}$-oxide (NMMO)/ $\mathrm{H}_{2} \mathrm{O}(87 / 13 \mathrm{wt} \%)$ (9). It has been demonstrated that Sprague Dawley (SD) rats treated with SCT-CF showed no epidermal hyperplasia, inflammatory cell infiltration, redness or edema on a surgical wound during 2 weeks of observation (10). In addition, SD rats treated with hydrocolloid membrane containing SCT (HCM-SCT) exhibited significantly faster re-epithelization, 
decreased epidermal thickness, decreased wound diameters and increased collagen levels (11). Cellulose membrane, obtained from the squirt skin of ascidians, was found to exert bioinductive effects on bone and mesenchymal tissues in the periosteum of cervical bone defects in SD rats (12). Furthermore, glycosaminoglycans, which may serve as a lubricant or a shock absorber, were successfully extracted from SCT using sodium phosphate at $105^{\circ} \mathrm{C}$ for $2 \mathrm{~h}$, followed by deproteinization with trichloroacetic acid or hydrochloride (7).

Bioactive compounds and extracts have also been prepared from SCT by extraction with different solvents. Chondroitin sulfate extracted from SCT was demonstrated to effectively suppress tumor necrosis factor- $\alpha$ (TNF- $\alpha)$-induced nuclear factor- $\kappa \mathrm{B}$ activation and the expression of two inflammatory factors [vascular cell adhesion molecule-1 (VCAM-1) and inducible nitric oxide synthase (iNOS)], through the blocking of Akt signals in JB6 $\mathrm{P}^{+}$cells derived from BALB/c mice (13). Moreover, carotenoids found in high concentrations in SCT were found to exhibit strong hydroxyl radical scavenging activities, reducing power as well as inhibitory effects against linoleic acid peroxidation (14). Furthermore, nine extracts collected from SCT using different solvents possessed high levels of tyrosinase inhibition and antioxidant activity due to the high total phenolic and flavonoid contents (8). However, to the best of our knowledge, no other studies have examined whether these extracts contribute to the homeostasis of the skin or the prevention of photoaging induced by ultraviolet (UV) radiation, although chondroitin sulfate and carotenoids have been reported to exert potential therapeutic effects upon inflammation and oxidative stress in vitro.

Thus, the protective effects of topically applied ethanol extract of SCT (EtSCT) on skin morphology, histopathological changes, endoplasmic reticulum (ER) stress, inflammation and the antioxidant status of the skin of hairless mice were examined in this study. The results presented herein provide strong evidence for the potential use of EtSCT in the prevention or alleviation of UV-induced skin aging, as well as the underlying mechanism of action.

\section{Materials and methods}

Preparation of EtSCT. SCT powder was prepared as previously described (15). Briefly, $330 \mathrm{~g} \mathrm{SCT}$ in $10 \% \mathrm{NaOH}$ aqueous solution $(9,900 \mathrm{ml})$ were boiled at $100^{\circ} \mathrm{C}$ for $2 \mathrm{~h}$ to remove sediments and debris, after collecting SCT from the beach of the South Sea in Goseong-gun, Korea. The samples were washed with distilled water three times, boiled in $5 \% \mathrm{CH}_{3} \mathrm{COOH}$ solution at $100^{\circ} \mathrm{C}$ for $2 \mathrm{~h}$ to neutralize the $\mathrm{NaOH}$ solution, and then washed with distilled water three times. The SCT samples were subsequently bleached by separate boiling and washing in $10 \% \mathrm{H}_{2} \mathrm{O}_{2}$ solution. Following a final wash with distilled water, the SCT samples were dried at $100-120^{\circ} \mathrm{C}$ for $2-3 \mathrm{~h}$, ground in a pin milling machine (DM-120, Youngin Scientific Co., Ltd., Seoul, Korea) using a proprietary commercial process in which they were passed through a combination of 30-mesh sieves for 10 min once, then 120 -mesh sieves for 10 min twice.

EtSCT was prepared as previously described (8). Briefly, the ethanol extracts were purified from $100 \mathrm{~g}$ of SCT powder for $3 \mathrm{~h}$ at $80^{\circ} \mathrm{C}$ using circulating extraction equipment (IKA Labortechnik, Staufen, Germany) after adding 1,000 $\mathrm{ml}$ of
$100 \%$ ethanol. After repeating this process three times, a solution of the extracts was concentrated to dry pellets in a rotary evaporator (Eyela, Tokyo, Japan) after filtering through Whatman No. 1 filter paper (Whatman International, Ltd., Maidstone, UK). The samples were then stored at $-80^{\circ} \mathrm{C}$ until further use.

Measurement of total phenolic and flavonoid contents. Total phenolic contents were measured by the Folin-Ciocalteu method, with slight modifications (16). Briefly, $1 \mathrm{ml}$ EtSCT solution was mixed with $5 \mathrm{ml}$ Folin-Ciocalteu reagent (Sigma-Aldrich Co., St. Louis, MO, USA) and then incubated at room temperature for $5 \mathrm{~min}$. The mixture was subsequently added to $15 \mathrm{ml} 20 \% \mathrm{Na}_{2} \mathrm{CO}_{3}$ and vortexed for $30 \mathrm{sec}$, after which the absorbance was repeatedly measured at $765 \mathrm{~nm}$ using a VersaMax plate reader (Molecular Devices, Sunnyvale, CA, USA). A standard calibration curve was prepared using different concentrations of gallic acid (Sigma-Aldrich Co.) and the concentration of total phenolic contents in EtSCT was presented as mg gallic acid equivalents of extract.

The flavonoid contents were measured as previously described (17). Briefly, $200 \mu \mathrm{l}$ of several different concentrations of EtSCT were mixed with $60 \mu \mathrm{l} 5 \% \mathrm{NaNO}_{2}$ and $60 \mu \mathrm{l}$ $10 \% \mathrm{AlCl}_{3}$ (both from Sigma-Aldrich Co.). Following incubation at $25^{\circ} \mathrm{C}$ for $5 \mathrm{~min}$, the mixture was added to $400 \mu \mathrm{l} 1 \mathrm{M}$ $\mathrm{NaOH}$ and the absorbance was repeatedly measured at $510 \mathrm{~nm}$ using a VersaMax plate reader (Molecular Devices). A standard calibration curve was then prepared using different concentrations of catechin (Sigma-Aldrich Co.). The concentration of flavonoid contents in Et-SCT was presented as mg catechin equivalents of extract.

Analysis of antioxidant activity. The scavenging activity of 2,2-diphenyl-1-picrylhydrazyl (DPPH) radicals was measured as previously described (18). Briefly, each sample (250 $\mu \mathrm{l})$ of EtSCT was mixed with $500 \mu 10.2 \mathrm{mM}$ DPPH (Sigma-Aldrich Co.) in 95\% ethanol solution or $100 \mu 1$ 95\% ethanol solution, and then incubated for $30 \mathrm{~min}$ at room temperature. Subsequently, the absorbance of the reaction mixture was measured at $517 \mathrm{~nm}$ using a VersaMax plate reader (Molecular Devices). The DPPH radical scavenging activity of the EtSCT was expressed as the percent decrease in absorbance relative to the control.

The reducing power of EtSCT was determined as previously described (19). Briefly, an appropriate volume (250 $\mu \mathrm{l})$ of EtSCT solution was mixed with $250 \mu 10.2 \mathrm{M}$ sodium phosphate buffer (pH 6.6) and $250 \mu 11 \%$ potassium ferricyanide, and then incubated at $50^{\circ} \mathrm{C}$ for $20 \mathrm{~min}$. Following centrifugation at $1,000 \mathrm{x}$ g for $10 \mathrm{~min}$, the supernatant was collected $(250 \mu \mathrm{l})$ and mixed with $50 \mu \mathrm{l}$ distilled water and $50 \mu \mathrm{l} 0.1 \%$ ferric chloride, and then incubated at room temperature for $10 \mathrm{~min}$. Finally, the absorbance of the reaction mixture was measured at $700 \mathrm{~nm}$ using a VersaMax plate reader (Molecular Devices). The reducing power was expressed as the percentage increase in rate with absorbance of the EtSCT-treated group relative to the absorbance level of a dimethyl sulfoxide (DMSO; Duchefa Biochemie B.V., Haarlem, Netherlands)-treated group.

The scavenging activity of nitric oxide (NO) was measured as previously described (20). Briefly, each sample of EtSCT (500 $\mu \mathrm{l})$ was mixed with $500 \mu \mathrm{l} 10 \mathrm{mM}$ sodium nitroprusside 
(Sigma-Aldrich Co.) and then incubated at $25^{\circ} \mathrm{C}$ for $150 \mathrm{~min}$. This mixture was then added to $500 \mu 11 \%$ sulfanilamide solution and $500 \mu 10.1 \% \mathrm{~N}$-(1-naphthyl)ethylenediamine dihydrochloride solution and incubated at room temperature for $10 \mathrm{~min}$. The absorbance of the reaction mixture was subsequently measured at $546 \mathrm{~nm}$ using a VersaMax plate reader (Molecular Devices). The NO scavenging activity of the EtSCT was expressed as the percentage absorbance relative to a control treated with DMSO.

Animal experiments. The animal protocols used in this study were reviewed and approved based on the ethical procedures and scientific care of animals set by the Pusan National University Institutional Animal Care and Use Committee (PNU-IACUC; approval no. PNU-2015-0812). Six-week-old male SKH-1 hairless mice were obtained from Orient Bio (Seongnam, Korea) and housed at the Pusan National University Laboratory Animal Resources Center, which is accredited by the Association for Assessment and Accreditation of Laboratory Animal Care International (AAALAC International; accredited unit no. 001525) in accordance with the United States National Institutes of Health Guidelines and the Korea Food and Drug Administration (KFDA; accredited unit no. 00231) and in accordance with the Laboratory Animals Act. All mice were given a standard irradiated chow diet (Purina Mills, Seoungnam, Korea) ad libitum, and were maintained in a specific pathogenfree state under a strict light cycle (lights on at 08:00 $\mathrm{h}$ and off at 18:00 h) at $23 \pm 2^{\circ} \mathrm{C}$ and $50 \pm 10 \%$ relative humidity.

The six-week-old hairless mice $(n=24)$ were first assigned to either a no radiation $(n=6)$ or a UV radiation $(n=18)$ group. The UV radiation group was then further divided into a vehicle-treated group, a low concentration EtSCT (LEtSCT)-treated group and a high concentration EtSCT (HEtSCT)-treated group. The two EtSCT-treated groups were treated with 5 or $10 \mathrm{mg} / \mathrm{ml}$ of EtSCT solution in olive oil $(1 \mathrm{ml})$ applied topically onto the dorsal skin of hairless mice three times a week for 13 weeks, whereas the vehicle-treated group was treated with a consistent volume of olive oil. At 13 weeks after the application of the vehicle, LEtSCT and HEtSCT treatments, the animals were sacrificed immediately using $\mathrm{CO}_{2}$ gas, to acquire blood, skin tissue, liver tissue and kidney tissue samples for further analysis.

$U V$ radiation and topical administration. The minimal erythemal dose (MED) from the UV irradiation device was determined as suggested in previous studies (21-23). Briefly, a UV irradiation device was made from a TL20W/12RS UV lamp and a Kodacel filter in a rectangular parallelepiped box. The UV lamp (Philips Lighting, Eindhoven, The Netherlands) had an emission spectrum of 274 to $380 \mathrm{~nm}$ that was composed of the following types of UV radiation: $10.2 \%$ UVC $(275-290 \mathrm{~nm})$, $53.5 \%$ UVB (290-320), 25.3\% UVA1 (320-340 nm) and 11.2\% UVA2 (340-380 nm). Kodacel Sheeting 6805 Product (Kodak, Rochester, NY, USA) was used to remove UVC wavelengths $<290 \mathrm{~nm}$. The irradiation intensity was measured at $30 \mathrm{~cm}$ from a light source using a UVX radiometer (UVP, LLC, Upland, CA, USA). To determine the $1 \mathrm{MED}$, the dorsal skin of the mice was exposed to different doses of UV light and the formation of erythema was evaluated after $24 \mathrm{~h}$. Skin aging was then induced by irradiation at 1 MED three times/week (Monday, Wednesday and Friday) for 13 weeks.
During the first 4 weeks, the dose of UV radiation was gradually increased by 1 MED per week from 1 to 4 MED, after which the mice received a constant dose (4 MED) of UV radiation from week 4 to 13 . During each step of treatment, the mice in the subset groups were treated with a topical application of $100 \mu \mathrm{l}$ of either vehicle, LEtSCT or HEtSCT onto their back skin, at $30 \mathrm{~min}$ after exposure to UV radiation.

Evaluation of wrinkle formation. Wrinkle formation was measured using a DETAX System II (MIXPAC) and Double-Stick Disc (3M Health Care, Neuss, Germany), according to a procedure established by our laboratory (23). After 12 weeks, skin surface impressions (replica) were prepared by applying silicon rubber in mixed liquid form secreted from a DETAX System II to the dorsal skin of mice. Each replica was captured by a digital camera in conjunction with the Leica Ez4HD (Leica Microsystems, Wetzlar, Germany) at x10 magnification. The depth and number of wrinkles on each skin impression were analyzed, after which the samples were classified into one of the four degrees suggested by Bissett et al (24). Specifically, grade 0 indicated no wrinkle formation, grade 1 indicated some shallow wrinkles, grade 2 indicated some wrinkles, and grade 3 indicated several deep wrinkles.

Measurement of transepidermal water loss (TEWL) and erythema index. Two factors related to skin homeostasis were assessed on the dorsal skin of each mouse using the appropriate devices (25). Specifically, TEWL was detected using a Corneometer CM825, and the erythema index was analyzed using a Mexameter MX18 (both from Courage and Khazaka Electronics, Cologne, Germany) according to the manufacturer's instructions. Each detection was performed three times on every site on the dorsal skin of the hairless mice.

Western blot analysis. The proteins prepared from the skin tissues of the vehicle-, LEtSCT- or HEtSCT-treated mice were separated by $4-20 \%$ sodium dodecyl sulfate-polyacrylamide gel electrophoresis (SDS-PAGE) for $3 \mathrm{~h}$, after which the resolved proteins were transferred to a nitrocellulose membrane for $2 \mathrm{~h}$ at $40 \mathrm{~V}$. Each membrane was then incubated separately with one of the following primary antibodies overnight at $4^{\circ} \mathrm{C}$ : anti-matrix metalloproteinase (MMP)-1/8 (sc-30069; 1:1,000) and anti-MMP-9 (sc-10737; 1:1,1000) (both from Santa Cruz Biotechnology, Inc., Santa Cruz, CA, USA); anti-collagen I (ab34710; 1:1,000; Abcam, Cambridge, UK); anti-ERK (sc-94; 1:1,000) and anti-phosphorylated (p-)ERK (sc-7383, 1:1,000) (both from Santa Cruz Biotechnology, Inc.); anti-c-Jun N-terminal kinase (JNK; 9252; 1:1,000), anti-p-JNK (9251; 1:1,000), anti-p38 (9212, 1:1,000) and anti-p-p38 (9211; 1:1,000) (all from Cell Signaling Technology, Danvers, MA, USA); anti-inositol-requiring enzyme (IRE)1 $\beta$ (sc-10511; 1:1,000; Santa Cruz Biotechnology, Inc.); eukaryotic initiation factor (eIF) $2 \alpha(9722 ; 1: 1,000)$ and anti-p-eIF2 $\alpha(9721 ; 1: 1,000)$ (both from Cell Signaling Technology); anti- $\beta$-actin (A5316; 1:3,000; Sigma-Aldrich Co.) and anti- $\alpha$-tubulin (T6074; 1:1,000; Sigma-Aldrich Co.). The membranes were then washed with washing buffer (137 mM NaCl, $2.7 \mathrm{mM} \mathrm{KCl}, 10 \mathrm{mM}$ $\mathrm{Na}_{2} \mathrm{HPO}_{4}, 2 \mathrm{mM} \mathrm{KH} \mathrm{PO}_{4}$ and $0.05 \%$ Tween-20) and incubated with horseradish peroxidase (HRP)-conjugated goat anti-rabbit IgG (81-6120; Zymed; Thermo Fisher Scientific, Waltham, MA, 
USA) at a 1:1,000 dilution at room temperature for $2 \mathrm{~h}$. Finally, the membrane blots were developed using a Chemiluminescence Reagent Plus kit (Pfizer, New York, NY, USA).

Histological analysis and optical microscopy. The dorsal skin in the region treated with the EtSCTs was collected and fixed with $10 \%$ formalin for $48 \mathrm{~h}$, embedded in paraffin wax, and then sectioned into $4 \mu \mathrm{m}$ thick slices. The skin sections were subsequently stained with hematoxylin and eosin (H\&E) (Sigma-Aldrich Co.), after which they were examined using a light microscope (DM500; Leica Microsystems) for evidence of alterations of histological structures. Additionally, the thickness of the epidermis and dermis as well as the number of adipocytes were measured using the Leica Application Suite (Leica Microsystems).

Toluidine blue staining. Mast cells were detected by staining with toluidine blue as previously described (26). After deparaffinization and dehydration, the skin sections were stained with $0.25 \%$ solution of toluidine blue (Sigma-Aldrich Co.) and examined by light microscopy for the presence of mast cells. The number of cells/specific area was measured using the Leica Application Suite (Leica Microsystems).

Immunohistochemical analysis. For immunohistochemical analysis, the dorsal skin in the region treated with the EtSCTs was collected and fixed with $10 \%$ formalin for $48 \mathrm{~h}$, embedded in paraffin wax, and then sectioned into $4 \mu \mathrm{m}$ thick slices. These sections were deparaffinized with xylene, rehydrated and pretreated for $30 \mathrm{~min}$ at room temperature with phosphate-buffered saline (PBS) blocking buffer containing $10 \%$ goat serum. The sections were then incubated with mouse anti-CD31 antibody (ab24590; Abcam) at a dilution of 1:100 in PBS blocking buffer. The antigen-antibody complexes were visualized with biotinylated secondary antibody (goat anti-mouse)-conjugated HRP (G21040; Invitrogen, Carlsbad, CA, USA) at a dilution of 1:100 in PBS blocking buffer. CD31 protein was detected using stable 3,3'-diaminobenzidine (DAB; ScyTek Laboratories Inc., Logan, UT, USA) and observed using the Leica Application Suite (Leica Microsystems).

Enzyme-linked immunosorbent assay (ELISA) for interleukin (IL)-6. The concentration of IL-6 in the skin tissue was measured using a Mouse IL-6 ELISA Max Deluxe kit (Biolegend, San Diego, CA, USA) according to the manufacturer's instructions. Briefly, the skin tissue (100 $\mu \mathrm{g})$ was prepared for analysis by gradually adding sucrose buffer (400 $\mu \mathrm{l}$ ) solution to tissue homogenate. The skin samples or standards and buffer $\mathrm{C}$ were incubated in a 96-well plate at room temperature for $2 \mathrm{~h}$ while shaking at $200 \mathrm{rpm}$, after which $100 \mu \mathrm{l}$ IL-6 detection antibody solution was added to each well and the samples were incubated at room temperature for $1 \mathrm{~h}$ with shaking. After washing, $100 \mu \mathrm{l}$ avidin-HRP D solution was added to each well and the plate was incubated at room temperature for $30 \mathrm{~min}$ with shaking. Next, $100 \mu \mathrm{l}$ substrate solution was added to each well and the plate was incubated for $10 \mathrm{~min}$ in the dark. The reaction was then quenched by the addition of $100 \mu \mathrm{l}$ Stop solution. Subsequently, the plates were analyzed by evaluating absorbance at $450 \mathrm{~nm}$ using a VersaMax plate reader (Molecular Devices).
Measurement of body and organ weights. Alterations in body weight were measured using an electronic balance (Mettler Toledo, Greifensee, Switzerland) once a week according to the KFDA guidelines. Finally, the weights of the kidneys and livers collected from the sacrificed mice were determined using the same method employed to detect the body weight.

Serum biochemical analysis. Following the final treatment, all mice fasted for $24 \mathrm{~h}$, after which blood was collected from the abdominal vein. Serum was obtained by centrifuging the blood after incubation for $30 \mathrm{~min}$ at room temperature. The serum concentrations of alkaline phosphatase (ALP), alanine transaminase (ALT), aspartate transaminase (AST), lactate dehydrogenase (LDH), blood urea nitrogen (BUN) and creatinine (CRE) were then assayed using a model 747 automated serum analyzer (Hitachi, Tokyo, Japan). All assays were conducted with fresh serum using standard enzymatic methods and all measurements were conducted in duplicate.

Analysis of malondialdehyde (MDA) levels. The MDA level was assayed using a Lipid Peroxidation (MDA) Assay kit (SigmaAldrich Co.) according to the manufacturer's instructions. Briefly, the skin tissue of each mouse was homogenized in MDA lysis buffer containing butylhydroxytoluene (BHT), after which the homogenates were stored at $-20^{\circ} \mathrm{C}$ until analysis. Serum collected from each mouse was mixed with $42 \mathrm{mM}$ sulfuric acid $\left(\mathrm{H}_{2} \mathrm{SO}_{4}\right)$ and $10 \%$ phosphotungstic acid solution, after which the samples were centrifuged at 13,000 x g for $3 \mathrm{~min}$. The pellet was resuspended with $\mathrm{dH}_{2} \mathrm{O}$ containing BHT. The sample or standards and thiobarbituric acid (TBA) solution (70 mM TBA, 5.0 $\mathrm{M}$ glacial acetic acid) were incubated in a microcentrifuge tube at $95^{\circ} \mathrm{C}$ for $60 \mathrm{~min}$, cooled to room temperature in an ice bath for $10 \mathrm{~min}$, and then absorbance at $450 \mathrm{~nm}$ was read using a VersaMax plate reader (Molecular Devices).

Analysis of superoxide dismutase (SOD) activity. The SOD activity in the skin tissue was detected using a calorimetric assay and the reagents in the SOD assay kit (Dojindo Molecular Technologies Inc., Kumamoto, Japan). Firstly, the skin tissue (100 mg) was homogenized in $600 \mu \mathrm{l}$ sucrose buffer $(0.25 \mathrm{~mol} / \mathrm{l}$ sucrose, 10 mmol/l HEPES, 1 mmol/l EDTA, pH 7.4) using a glass homogenizer. The lysate was then harvested from the mixture by centrifugation at $10,000 \mathrm{x}$ g for $60 \mathrm{~min}$ and stored at $-70^{\circ} \mathrm{C}$ until needed for the enzyme activity assay. To measure SOD activity, the sample lysate was diluted with dilution buffer or saline as follows: $1,1 / 5,1 / 5^{2}, 1 / 5^{3}, 1 / 5^{4}, 1 / 5^{5}$ and $1 / 5^{6}$. Next, $25 \mu \mathrm{l}$ aliquots of each sample solution were placed in 96 -well plates, after which $200 \mu \mathrm{l}$ of the WST working solution was added. In addition, an enzyme working solution $(20 \mu \mathrm{l})$ was added to each well and the samples were then mixed thoroughly. The enzyme reaction was induced by incubating the mixture plate at $37^{\circ} \mathrm{C}$ for $20 \mathrm{~min}$, and then measuring absorbance at $450 \mathrm{~nm}$ using a spectrophotometer. SOD activity was calculated directly using the following equation: SOD activity [inhibition $\operatorname{rate}(\%)]=\left[\left(\mathrm{A}_{\text {blank } 1}-\mathrm{A}_{\text {blank } 3}\right)-\left(\mathrm{A}_{\text {sample }}-\mathrm{A}_{\text {blank } 2}\right)\right] /\left(\mathrm{A}_{\text {blank } 1}-\mathrm{A}_{\text {blank } 3}\right) \times 100$ ( $A_{\text {blank } 1}$, absorbance of blank 1; $A_{\text {blank 2 }}$, absorbance of blank 2; $\mathrm{A}_{\text {blank } 3}$, absorbance of blank 3; $\mathrm{A}_{\text {sample }}$, absorbance of sample).

Statistical analysis. One-way ANOVA was used to determine the significant differences between the no radiation group and 
Table I. Concentration of total flavonoids and phenolic contents in EtSCT.

\begin{tabular}{lc}
\hline Categories & Concentration $(\mathrm{mg} / \mathrm{ml})$ \\
\hline Flavonoids & 15.3 \\
Phenolic contents & 36.8 \\
\hline
\end{tabular}

EtSCT, ethanol extract of $S$. clava tunics.

Table II. Antioxidant activity of EtSCT.

\begin{tabular}{lc}
\hline Categories & Level (\%) \\
\hline Reducing power & 3.1 \\
DPPH radical scavenging activity & 92.7 \\
NO scavenging activity & 15.6 \\
\hline
\end{tabular}

DPPH; 2,2-diphenyl-1-picrylhydrazyl; NO, nitric oxide; EtSCT, ethanol extract of S. clava tunics.

the UV radiation groups (SPSS for Windows, release 10.10, standard version; SPSS Inc., Chicago, IL, USA). In addition, differences in the responses of the vehicle-treated group and the EtSCT-treated groups within the UV radiation group were evaluated using a post-hoc test (SPSS for Windows, release 10.10, standard version; SPSS Inc.) of the variance and significance levels. All values are reported as the means \pm SEM. A p-value of $<0.05$ was considered to indicate a statistically significant difference.

\section{Results}

Antioxidant activity and total flavonoid and phenolic levels in EtSCT. As shown in Table I, EtSCT contained high concentrations of two important antioxidants, flavonoids $(15.3 \mathrm{mg} / \mathrm{ml})$ and phenolics $(36.8 \mathrm{mg} / \mathrm{ml})$. The free radical scavenging activity of DPPH and NO, as well as the reducing power of EtSCT were analyzed following mix with single doses of EtSCT. High DPPH scavenging activity $(92.7 \%)$ was measured in EtSCT. In addition, the reducing power and NO scavenging activity of EtSCT were found to be 3.1 and $15.6 \%$, respectively (Table II). Taken together, these results indicate that EtSCT has strong DPPH and NO scavenging activity, as well as reducing power, and therefore has the potential for use as an antioxidant.

Suppression of photodamage in response to the topical application of EtSCT. Alterations in skin phenotypes were evaluated in the vehicle- or EtSCT-treated mice after 13 weeks of treatment to determine whether EtSCT application inhibits photoaging induced by UV radiation. Following exposure to UV radiation, the wrinkle score, including the depth and number of wrinkles, was significantly higher in the UV + vehicle-treated group than in the no radiation group. Conversely, there were significantly fewer wrinkles induced by UV radiation in the LEtSCT- and HEtSCT-treated mice (Fig. 1A and B). In addition, the level
$\mathbf{A}$
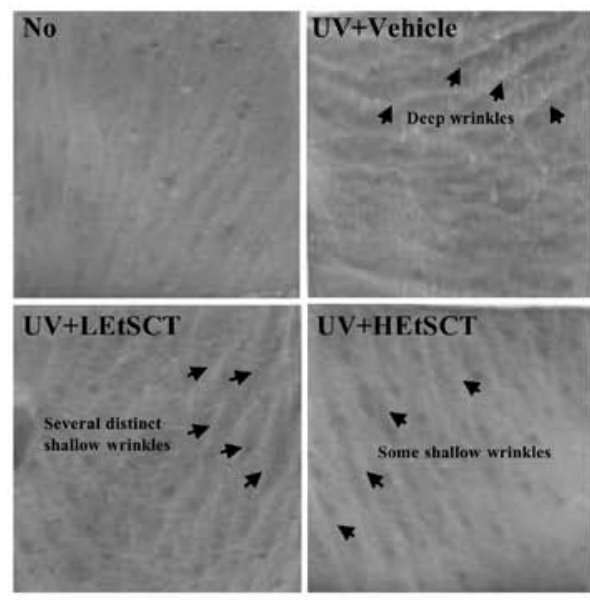

B

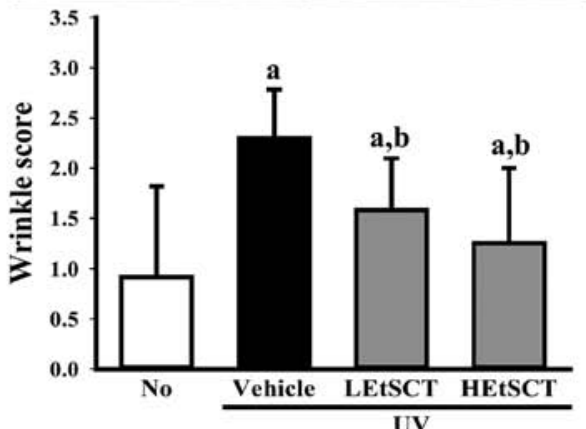

C

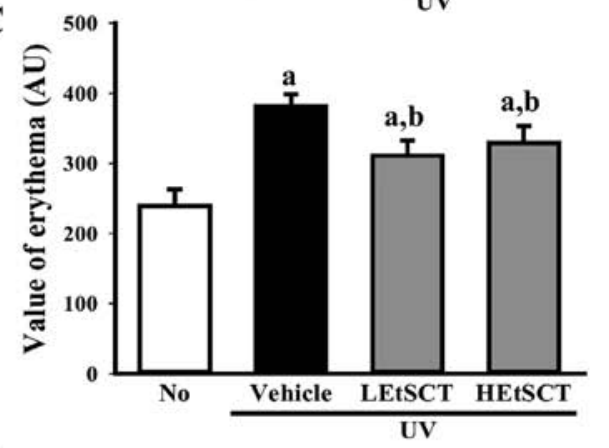

D

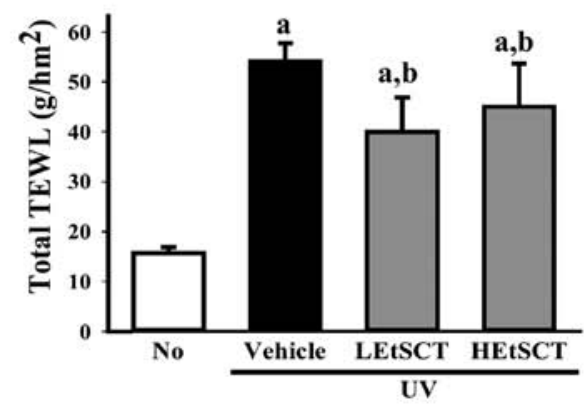

Figure 1. Inhibition of UV-induced wrinkle formation and physiological alteration of intact skin in response to topical application of ethanol extract of S. clava tunic (EtSCT) to hairless mice. (A and B) Wrinkle formation was measured by replica grading during the final week. The level of wrinkles was assessed using the scoring system suggested by Bissett et al (24) (grade 0, no wrinkles; grade 1, a few shallow wrinkles; grade 2, some wrinkles; grade 3, several deep wrinkles). (C) The erythema index and (D) transepidermal water loss (TEWL) in the dorsal skin of hairless mice were analyzed in triplicate using the appropriate device as described in the Materials and methods. The data represent the means $\pm \mathrm{SD}$ of three replicates. ${ }^{\mathrm{a}} \mathrm{p}<0.05$ compared to no radiation (No) group; ${ }^{\mathrm{b}} \mathrm{p}<0.05$ compared to the $\mathrm{UV}+$ vehicle-treated group. LEtSCT, low concentration EtSCT; HEtSCT, high concentration EtSCT.

of TEWL and the erythema index were significantly higher in the mice exposed to UV light when this level was compared 
A
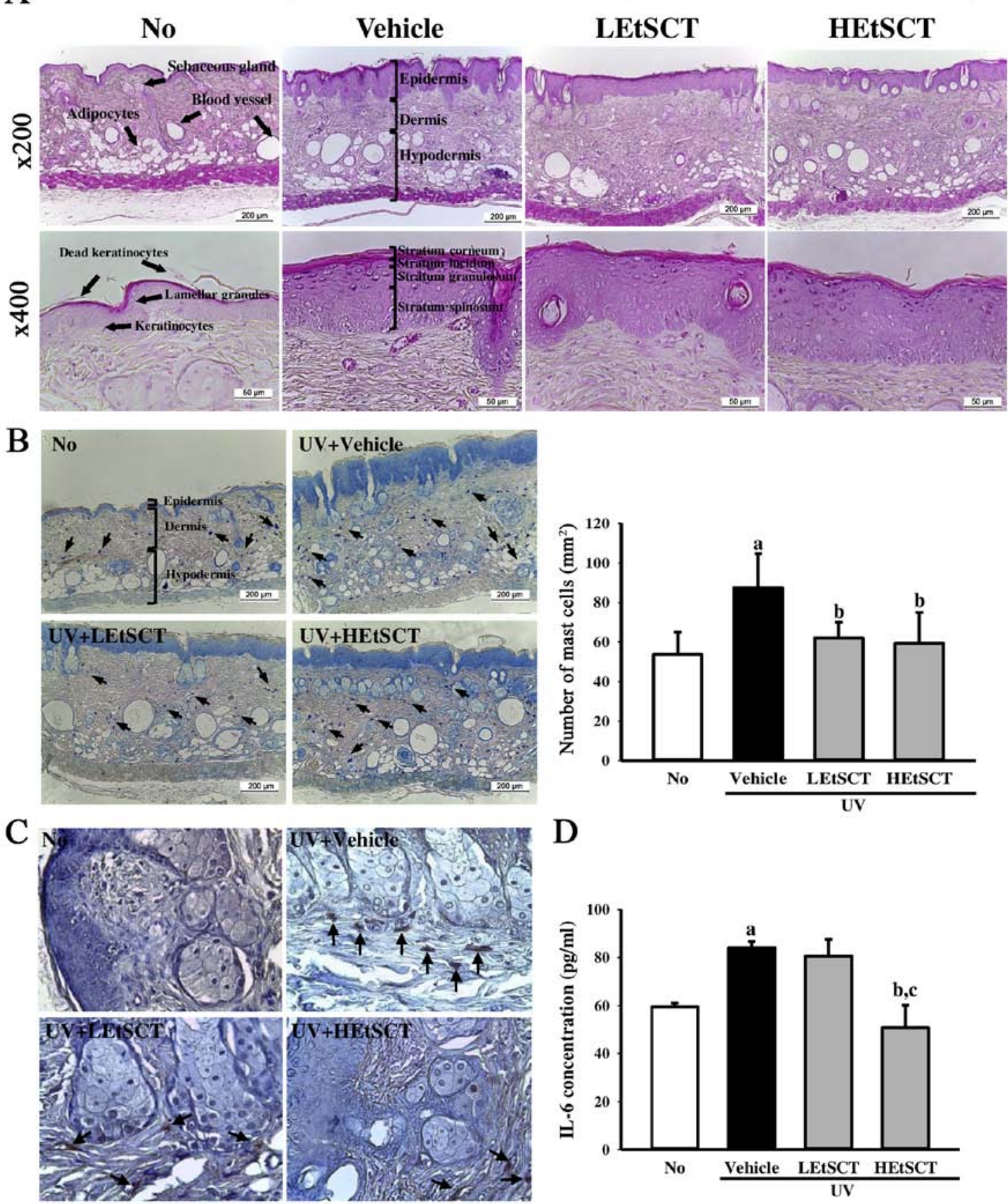

D

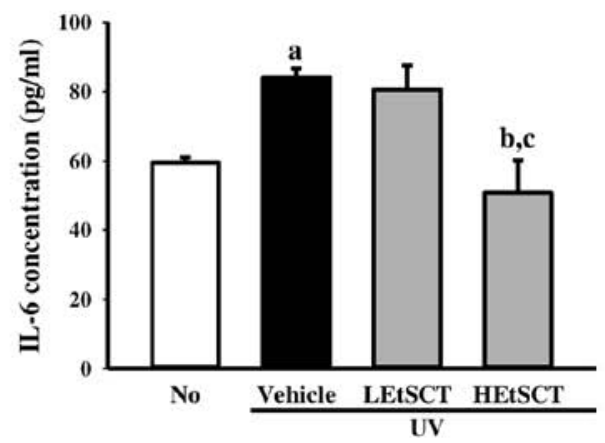

Figure 2. Histopathological structure of skin samples from hairless mice following topical application of ethanol extract of S. clava (EtSCT) and analysis of UV-irradiated skin inflammation in the hairless mice. (A) The dorsal skin tissues of hairless mice were fixed in $4 \%$ formaldehyde and stained with $\mathrm{H} \& \mathrm{E}$ solution. Histological alterations on the slides were observed at x200 magnification (upper panels) and x400 magnification (lower panels). (B) After final treatment, skin tissues were collected from the control, UV + vehicle, UV + LEtSCT and UV + HEtSCT groups. Slide sections of skin tissue were stained with $0.25 \%$ toluidine blue and observed at a magnification of x200. (C) Immunohistochemistry for CD31 protein. The distribution and intensity of CD31-specific antibody in a part of the dermis was then observed at x400 magnification. Black arrows indicate stained cells. (D) Determination of interleukin (IL)-6 concentration. After collecting skin tissue, the concentration of IL- 6 was determined in the homogenate mixture collected from the skins of mice using a IL-6 ELISA kit that detected IL- 6 at 2 pg/ $\mathrm{ml}$. Data represent the means $\pm \mathrm{SD}$ of three replicates. ${ }^{\mathrm{a}} \mathrm{p}<0.05$ compared to no radiation (No) group; ${ }^{\mathrm{b}} \mathrm{p}<0.05$ compared to the UV + vehicle-treated group; ${ }^{\mathrm{c}} \mathrm{p}<0.05$ compared to the UV + LEtSCT-treated group. LEtSCT, low concentration EtSCT; HEtSCT, high concentration EtSCT.

with that of the no radiation group. However, these levels were significantly lower in the UV + EtSCT-treated groups than in the UV + vehicle-treated group, although this effect was not dose-dependent (Fig. 1C and D). Therefore, the topical application of EtSCT to the dorsal skin of hairless mice effectively inhibited wrinkle formation while preventing water loss and decreasing the erythema index.
Effects of EtSCT on the histological structures of skin samples from hairless mice. It has been previously demonstrated that significant histological changes in the dorsal skin of mice were induced by UV radiation (27). Thus, in the present study, the effects of the topical application of EtSCT on the histological structure of mouse skin were examined. Following $U V$ radiation exposure, the epidermis and dermis were significantly thicker 
Table III. Alterations in the various histological factors in skin tissue treated with UV + EtSCT.

\begin{tabular}{|c|c|c|c|c|}
\hline \multirow[b]{2}{*}{ Categories } & \multirow[b]{2}{*}{ No radiation } & \multicolumn{3}{|c|}{ UV } \\
\hline & & Vehicle & LEtSCT & HEtSCT \\
\hline Epidermis Th $(\mu \mathrm{m})$ & $43.2 \pm 6.88$ & $165.7 \pm 24.18^{\mathrm{a}}$ & $97.9 \pm 8.50^{\mathrm{a}, \mathrm{b}}$ & $64.2 \pm 11.62^{\mathrm{b}, \mathrm{c}}$ \\
\hline Dermis Th $(\mu \mathrm{m})$ & $251.3 \pm 27.25$ & $355.0 \pm 29.27^{\mathrm{a}}$ & $305.8 \pm 23.21$ & $313.0 \pm 16.60$ \\
\hline $\mathrm{SC} \mathrm{Th}(\mu \mathrm{m})$ & $5.3 \pm 0.90$ & $18.4 \pm 0.76^{\mathrm{a}}$ & $13.4 \pm 1.66^{\mathrm{a}, \mathrm{b}}$ & $9.6 \pm 0.75^{\mathrm{a}-\mathrm{c}}$ \\
\hline $\mathrm{SL} \mathrm{Th}(\mu \mathrm{m})$ & $2.8 \pm 0.30$ & $5.3 \pm 1.12^{\mathrm{a}}$ & $3.9 \pm 0.69$ & $4.4 \pm 0.52$ \\
\hline $\mathrm{SG} \mathrm{Th}(\mu \mathrm{m})$ & $12.7 \pm 2.36$ & $40.9 \pm 4.62^{\mathrm{a}}$ & $30.3 \pm 4.98^{\mathrm{a}, \mathrm{b}}$ & $32.2 \pm 6.54^{\mathrm{a}, \mathrm{b}}$ \\
\hline $\mathrm{SS} \mathrm{Th}(\mu \mathrm{m})$ & $30.3 \pm 4.98$ & $49.6 \pm 6.03^{\mathrm{a}}$ & $34.8 \pm 3.64$ & $38.5 \pm 4.07$ \\
\hline No. of adipocytes & $55.6 \pm 5.85$ & $29.0 \pm 9.16^{\mathrm{a}}$ & $50.2 \pm 11.23^{b}$ & $42.4 \pm 9.76^{\mathrm{b}}$ \\
\hline Average area of adipocytes $\left(\mathrm{cm}^{2}\right)$ & $36.8 \pm 22.32$ & $19.9 \pm 16.14^{\mathrm{a}}$ & $15.2 \pm 12.78^{\mathrm{a}}$ & $21.0 \pm 11.26^{\mathrm{a}}$ \\
\hline
\end{tabular}

The data is reported as the means \pm SD from three replicates. ${ }^{a} \mathrm{p}<0.05$ compared with the control (no radiation) group; ${ }^{\mathrm{b}} \mathrm{p}<0.05$ compared with the $\mathrm{UV}+$ vehicle treated group; ${ }^{\mathrm{p}} \mathrm{p}<0.05$ compared with the UV + LEtSCT group. Th, thickness; SC, stratum corneum; SL, stratum lucidum; SG, stratum granulosum; SS, stratum spinosum; EtSCT, ethanol extract of $S$. clava tunics; LEtSCT, low concentration EtSCT; HEtSCT, high concentration EtSCT; UV, ultraviolet.

than in the no radiation group. However, the LEtSCT- and HEtSCT-treated groups showed decreased epidermal and dermal thickness, although their ratio was greater in the epidermis than the dermis (Fig. 2A and Table III). This pattern of changes to the epidermis was also detected in the subregions of the epidermis, including the stratum corneum, stratum lucidum, stratum granulosum and stratum spinosum (Fig. 2A). Conversely, the number of adipocytes in the subcutaneous region was also significantly lower in the UV + vehicle-treated group. However, these levels were increased in the UV + LEtSCT- and UV + HEtSCTtreated groups relative to that in the UV + vehicle-treated group, although the average area of adipocytes was maintained at a constant level (Fig. 2A and Table III). Taken together, these results suggest that the topical application of EtSCT for 13 weeks induced a decrease in the thickness of the epidermis and dermis, as well as an increase in the number of adipocytes following UV exposure.

Effects of EtSCT on skin inflammation. To examine the suppressive effect of EtSCT on skin inflammation induced by UV radiation, alterations in the mast cell number, CD31 expression and IL-6 concentration were measured in the skin tissues of mice. Many mast cells in the dermis region were stained blue in the UV + vehicle-treated group relative to the no radiation group. However, the number of mast cells was significantly lower in the UV + LEtSCT-treated (62.0\%) and the UV + HEtSCT-treated (59.3\%) groups (Fig. 2B). Moreover, changes in the number of CD31-stained cells were very similar to those of mast cells in the dermis region. The UV + EtSCTtreated groups showed a decrease in the number of CD31-stained cells relative to the $\mathrm{UV}$ + vehicle-treated group (Fig. 2C). A similar pattern was also observed in the expression of IL-6, although the degree of decrease or increase varied in each group. The expression of IL-6 decreased markedly only in the UV + HEtSCT-treated group (Fig. 2D). Overall, the above results indicate that skin inflammation induced by UV radiation may be suppressed by the topical application of EtSCT for 13 weeks.
Effect of topical application of EtSCT on the mechanism responsible for the regulation of collagen contents. Alterations in the collagen content of the extracellular matrix (ECM) are primarily responsible for the clinical manifestations of skin aging such as wrinkles, sagging and laxity $(28,29)$. Therefore this study examined whether the regulatory mechanism of collagen I contents in skin tissue was recovered by the topical application of EtSCT for 13 weeks. The collagen I level in the UV + vehicle-treated group was lower than that in the no radiation group. However, these levels were significantly higher in the UV + LEtSCT- and the UV + HEtSCT-treated groups (approximately 2.2 or 2.7 -fold, respectively) than in the UV + vehicle-treated group (Fig. 3).

To examine whether alterations in collagen expression accompanied changes in the collagenase and elastinase in skin tissue treated with EtSCT, the expression of MMP in the skin of the UV + EtSCT-treated groups was measured. In the $\mathrm{UV}+$ vehicle-treated group, the level of MMP-1 expression was significantly higher than that in the no radiation group. However, MMP-1 levels decreased significantly by $65 \%$ in the group treated with HEtSCT alone, whereas this level was slightly increased in the UV + LEtSCT-treated group (Fig. 3). Conversely, the expression pattern of elastinase (MMP-9) was different from that of MMP-1 in the UV + HEtSCT-treated group. The LEtSCT- and HEtSCT-treated groups did not show a significant increase in MMP-9 expression in the UV + EtSCT-treated groups, although the levels in these groups were higher than those in the no radiation group (Fig. 3). Taken together, these results suggest that the topical application of EtSCT induces the recovery of collagen I content by suppressing MMP-1 expression.

Effects of EtSCT on the mitogen-activated protein (MAP) kinase signaling pathway activated by $U V$ radiation. To determine whether activation of the MAP kinase signaling pathway following exposure to UV radiation was inhibited by the topical application of EtSCT for 13 weeks, the expression of key proteins belonging to this pathway were measured in the dorsal skin of EtSCT-treated mice. Western blot analysis using specific 

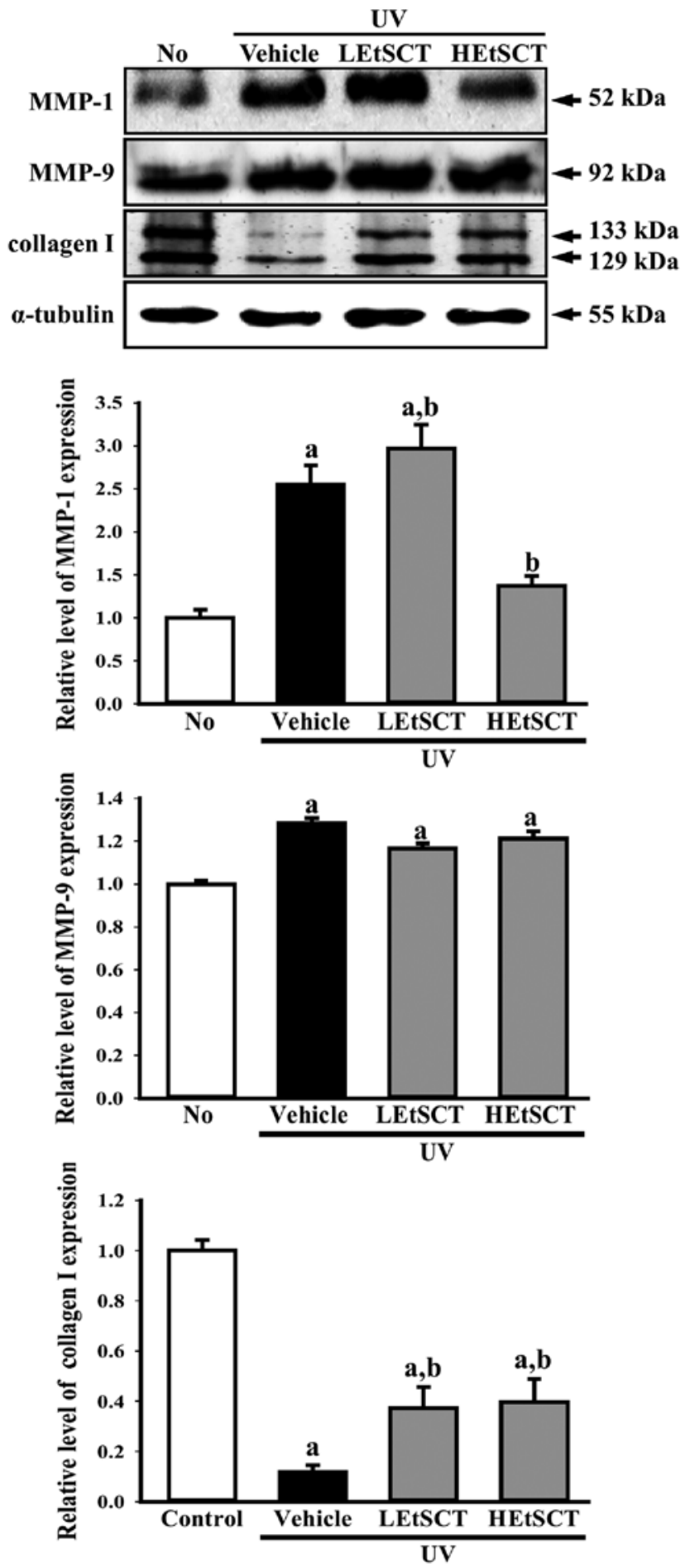

Figure 3. Expression of matrix metalloproteinase (MMP)-1, MMP-9 and collagen I. The total tissue lysates were prepared from the skin tissues of the control, $\mathrm{UV}+$ vehicle, $\mathrm{UV}+\mathrm{LEtSCT}$ and UV + HEtSCT groups as described in the Materials and methods. The intensity of each band was determined using an imaging densitometer and the relative level of each protein was calculated based on the intensity of $\alpha$-tubulin protein as an endogenous control. Data represent the means \pm SD of three replicates. ${ }^{a} \mathrm{p}<0.05$ compared with the no radiation (No) group; ${ }^{b} \mathrm{p}<0.05$ compared with the UV + vehicle-treated group. LEtSCT, low concentration ethanol extract of $S$. clava; HEtSCT, high concentration ethanol extract of S. clava.

antibodies revealed different phosphorylation patterns among the three proteins (ERK, JNK and p38) in the subset groups. In the case of ERK and JNK, the phosphorylation level was higher in the UV + vehicle-treated group than in the no radiation group. Following topical application of EtSCT, this level decreased significantly, although the decrease did not differ among groups (Fig. 4). In the case of p38, the phosphorylation level was slightly decreased in the UV + vehicle-treated group when compared with that of the no radiation group. However, EtSCT treatment induced a marked increase in the phosphorylation level of $\mathrm{p} 38$, with the highest level of this protein being observed in the HEtSCT-treated group (Fig. 4). The results of the present study suggest that EtSCT application inhibits ERK and JNK phosphorylation and activates p38 phosphorylation.

Effects of EtSCT on the ER stress signaling pathway of following exposure to $U V$ radiation. To determine whether the topical application of EtSCT stimulates two different types of signaling in the ER stress pathway, the levels of key proteins in the IRE1 and protein kinase R-like endoplasmic reticulum kinase (PERK, also known as eukaryotic translation initiation factor 2- $\alpha$ kinase 3) signaling pathway were monitored in the skin tissues from all groups of mice by performing western blot analysis with the corresponding antibodies. In the case of the IRE1 signaling pathway, the UV + vehicle-treated group showed higher protein expression of IRE1 $\beta$ than in the no radiation group. The expression of this protein was significantly lower in UV + EtSCT-treated mice, and the greatest decrease was observed in the HEtSCT-treated group. However, the phosphorylation level of eIF $2 \alpha$ was maintained in the LEtSCT- and HEtSCT-treated mice (Fig. 5A and B). Taken together, these results suggest that the topical application of EtSCT effectively inhibits the IRE1 signal within the ER stress signaling pathway.

Antioxidant activity of skin tissue. Finally, we examined the inhibitory effects of EtSCT on oxidative stress induced by UV radiation. To accomplish this, the MDA concentration and SOD activity were measured in the skin tissue of hairless mice. The concentration of MDA in the serum and skin tissue was 190 and 26\% higher, respectively, in the UV + vehicle-treated group than in the no radiation group, whereas the level decreased significantly in a dose-dependent manner in the skin of EtSCT-treated groups. The highest level of decrease was detected in the HEtSCT-treated group (Fig. 6A). The activity of SOD showed the opposite pattern to the MDA concentration. Specifically, the UV + vehicle-treated group showed lower $(22 \%)$ SOD activity than the no radiation group, although this level was significantly higher in all EtSCT treated groups (Fig. 6B). Overall, these results suggest that EtSCT treatment inhibits the oxidative stress and lipid peroxidation induced by $\mathrm{UV}$ radiation.

Toxicity analysis of topically applied EtSCT. Changes in body weight, serum biochemical indicators and histological structures in the hairless mice treated with UV + EtSCT were evaluated in order to determine the toxicity of EtSCT. Although the body weights of the mice in the EtSCT-treated groups were slightly higher than those of the mice in the control, there were no significant differences in body weight between the treated groups at 13 weeks (Table IV). The hepatotoxicity of EtSCT was determined by measuring ALP, ALT and AST concentrations, as well as by observing the histopathological 

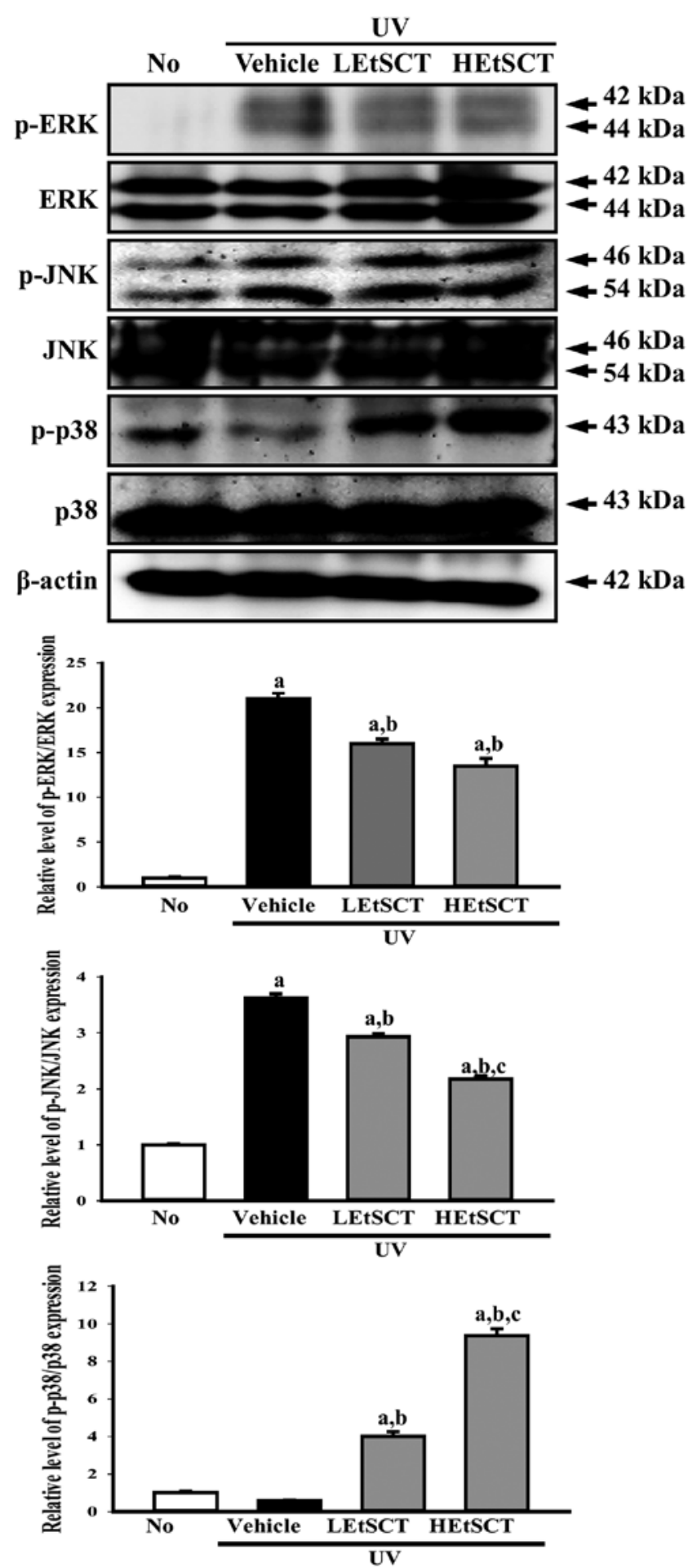

Figure 4. Analysis of the mitogen-activated protein (MAP) kinase signaling pathway. Total tissue lysates were prepared from the skin tissues of the control, $\mathrm{UV}+$ vehicle, UV + LEtSCT and UV + HEtSCT groups as described in the Materials and methods. The intensity of each band was determined using an imaging densitometer and the relative level of each protein was calculated based on the intensity of actin protein as an endogenous control. Data represent the means \pm SD of three replicates. ${ }^{a} p<0.05$ compared with the no radiation (No) group; ${ }^{b} \mathrm{p}<0.05$ compared with the UV + vehicle-treated group. ${ }^{c} \mathrm{p}<0.05$ compared with the UV + LEtSCT-treated group. LEtSCT, low concentration ethanol extract of S. clava; HEtSCT, high concentration ethanol extract of S. clava; p-, phosphorylated.

alterations in the mouse livers. No significant alterations in the three liver enzymes were detected in the UV + EtSCT-treated
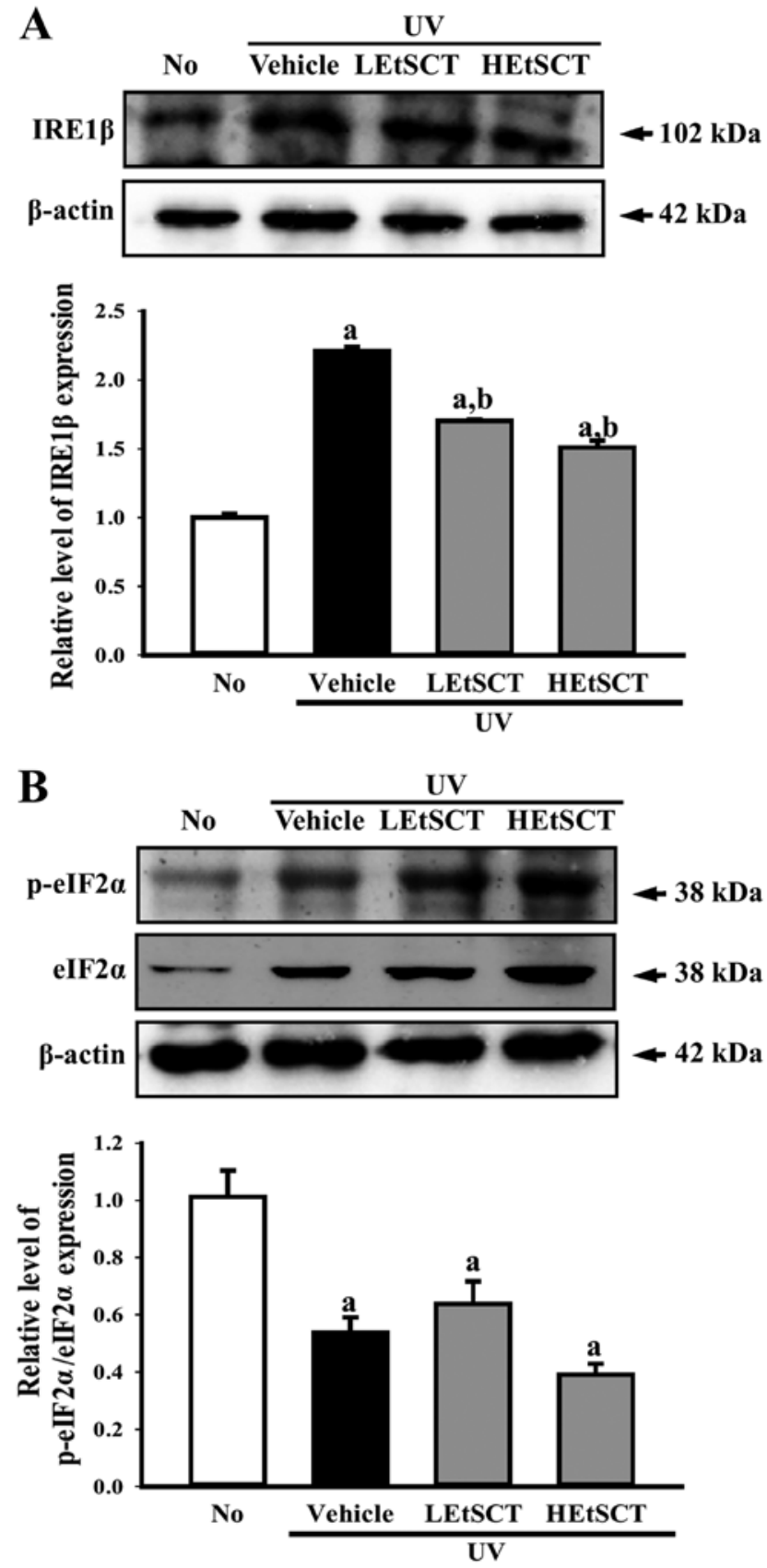

Figure 5. Analysis of UV-induced endoplasmic reticulum (ER) stress. Total tissue lysates were prepared from the skin tissues of the control, UV + vehicle, $\mathrm{UV}+\mathrm{LEtSCT}$ and UV + HEtSCT groups as described in the Materials and methods. The expression levels of (A) inositol-requiring enzyme (IRE) $1 \beta$, (B) phosphorylated (p-) eukaryotic initiation factor (eIF) $2 \alpha$ and eIF2 $\alpha$ were detected by the specific antibody. The intensity of each band was determined using an imaging densitometer and the relative level of each protein was calculated based on the intensity of actin protein as an endogenous control. Data represent the means $\pm \mathrm{SD}$ of three replicates. ${ }^{\mathrm{a}} \mathrm{p}<0.05$ compared with the no radiation (No) group; ${ }^{\mathrm{b}} \mathrm{p}<0.05$ compared with the $\mathrm{UV}+$ vehicle-treated group. LEtSCT, low concentration ethanol extract of S. clava; HEtSCT, high concentration ethanol extract of S. clava.

groups (Table IV). Histological alterations in the liver sections stained with H\&E were observed upon microscopic evaluation. No significant pathological changes were detected in the liver tissue of mice in any groups (data not shown).

The concentrations of BUN and CRE, which indicate kidney toxicity, showed a similar pattern, with a constant level 

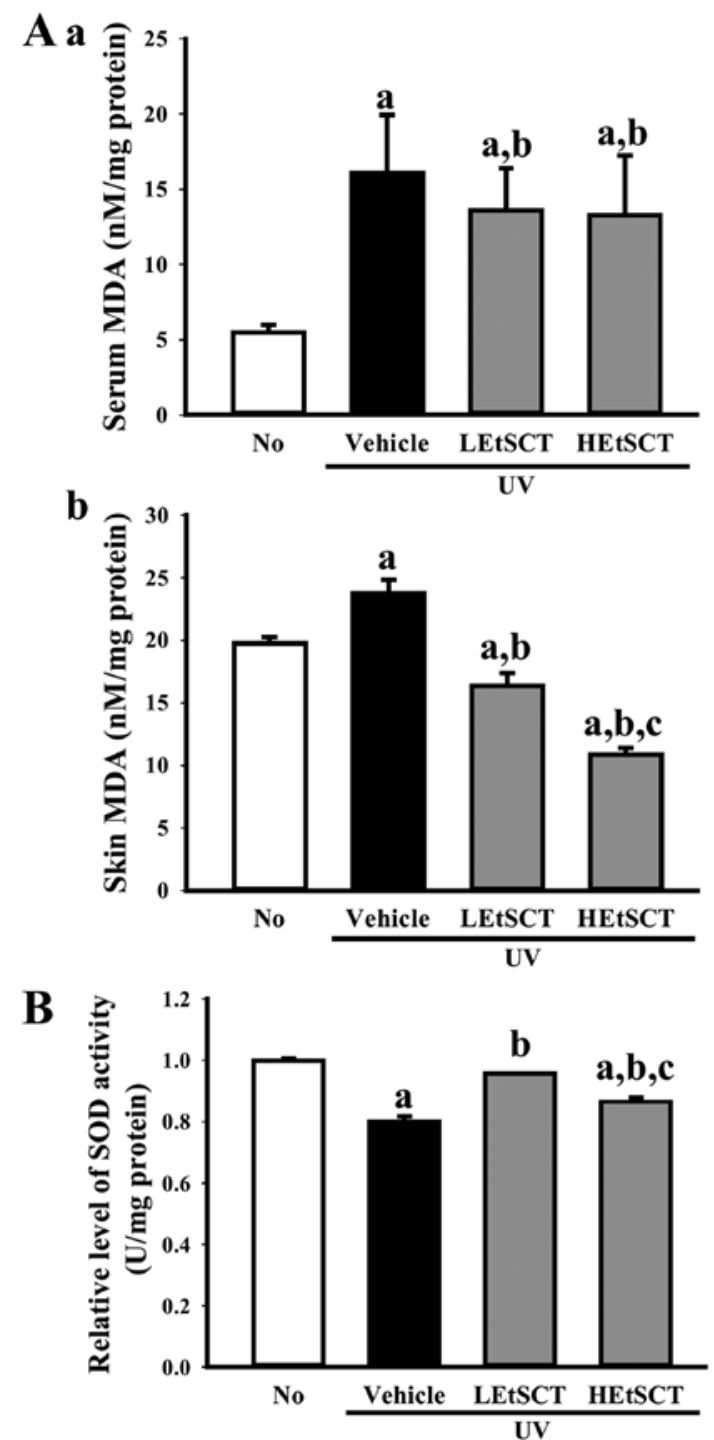

Figure 6. Alteration of oxidant stress parameters in the examined group. (A) The level of malondialdehyde (MDA) was determined in the serum and skin tissue collected from mice using a lipid peroxidation assay kit capable of detecting MDA at $0.1-20 \mathrm{nmole} / \mathrm{mg}$. (B) The expression level of SOD was measured in the homogenate of the skin tissue collected from subset groups. The intensity of each band was determined using an imaging densitometer and the relative level of each protein was calculated based on the intensity of actin protein as an endogenous control. Data represent the means \pm SD of three replicates. ${ }^{a} \mathrm{p}<0.05$ relative to the no radiation (No) group; ${ }^{b} \mathrm{p}<0.05$ relative to the UV + vehicle-treated group; ${ }^{c} \mathrm{p}<0.05$ compared with the $\mathrm{UV}+$ LEtSCT-treated group. LEtSCT, low concentration ethanol extract of S. clava; HEtSCT, high concentration ethanol extract of $S$. clava.

of these factors maintained in the subset groups (Table IV). Furthermore, microscopic observation revealed no specific pathological symptoms in any of the EtSCT-treated groups (data not shown). These results suggest that EtSCT treatment for 13 weeks does not induce specific toxic effects in the livers or kidneys of hairless mice.

\section{Discussion}

Both the passage of time (intrinsic aging) and cumulative exposure to external influences (extrinsic aging), such as UV radiation and smoking, may induce skin aging $(30,31)$. Among factors leading to extrinsic aging, UV radiation is the most well-known cause of skin damage, resulting in deep wrinkles, roughness, laxity and pigmentation (31). However, skin aging induced by UV radiation may be effectively prevented by antioxidants and mixtures originating from natural products (32). In this study, we investigated the novel effects of EtSCT on $\mathrm{UV}$-induced skin aging. Although the antioxidant activity of various compounds and extracts derived from SC have been investigated in several studies $(9,33-36)$, there have been no investigations of the therapeutic effects of SCT on photoaging induced by UV radiation, to the best of our knowledge. In this study, EtSCT was shown to have the ability to prevent skin aging, including wrinkle formation, increasing epidermal thickness, skin inflammation, activation of the MAP kinase pathway and enhanced lipid oxidation, through the upregulation of antioxidant activity in the skin.

Many phytochemicals that are sources of natural antioxidants, such as phenolic diterpenes, flavonoids, tannins and polyphenolic acids, have been reported to be potential therapeutic agents for the treatment of cancer, pathological angiogenesis and cardiovascular disease $(37,38)$. In a previous study, the concentrations of flavonoids and phenolic contents were measured in SCT extracts collected using several different solvents. The highest flavonoid contents were detected in chloroform extract $(23.0 \mathrm{mg} / \mathrm{g})$, followed by $\mathrm{n}$-butanol extract $(19.1 \mathrm{mg} / \mathrm{g})$, acetone extract $(17.2 \mathrm{mg} / \mathrm{g})$, ethanol extract $(15.6 \mathrm{mg} / \mathrm{g})$ and $\mathrm{n}$-hexane extract $(8.9 \mathrm{mg} / \mathrm{g})(8)$. In addition, the total phenolic content in hot water extract of SCT was $46.6 \mathrm{mg} / \mathrm{g}$, whereas it was $37.5 \mathrm{mg} / \mathrm{g}$ in ethanol extract (8). However, carotenoid extract purified with acetone solvent contained 11.1-13.8 $\mu \mathrm{g} / \mathrm{g}$ of total phenolic content (14). In the present study, we used ethanol extract to examine the therapeutic effects against skin aging. These extracts showed similar flavonoid and total phenolic contents to previous findings (8).

Measurements of DPPH and NO scavenging activity as well as reducing power are widely used to evaluate antioxidant activity (39). Extracts collected from SCT using different solvents showed various levels of antioxidant activity in previous reports. The highest levels of DPPH radical scavenging activity were detected in acetone, ethylacetate, chloroform and n-butanol extract, and ethanol extract showed $93.3 \%$ activity. However, the greatest NO radical scavenging activity was measured in n-hexane extract, while that of ethanol extract and methanol extract was 15.0 and $9.7 \%$, respectively. The reducing power of autoclave extract was highest (100\%), followed by that of hot water extract (97.8\%), n-butanol extract (4.6\%), chloroform extract (3.1\%) and ethanol extract (2.9\%) (8). Moreover, the carotenoid-enriched sample showed a scavenging capacity of $29.9 \%$ when tested against $5 \mathrm{mM}$ DPPH radical for $30 \mathrm{~min}$ as well as strong reducing power with an OD of 1.025 against a concentration of $120 \mu \mathrm{g} / \mathrm{ml}$ (14). The results of this study are in agreement with those reported by Lee et al (8), whereas they differ from those observed by Nacional et al (14). The differences among samples may have been due to differences in the extraction solvents and test systems employed.

Although many antioxidants and anti-photoaging compounds that effectively prevent photodamage of the skin are available, few studies have demonstrated correlations between natural extracts with antioxidant activity and protection of the skin against wrinkle formation, TEWL and erythema. Topical 
Table IV. Toxicity analysis of topically applied EtSCT to hairless mice.

UV

\begin{tabular}{|c|c|c|c|c|}
\hline \multirow[b]{2}{*}{ Categories } & \multirow[b]{2}{*}{ No radiation } & \\
\hline & & Vehicle & LEtSCT & HEtSCT \\
\hline Body weight (g) & $34.9 \pm 0.64$ & $34.2 \pm 1.89$ & $36.2 \pm 0.70$ & $35.1 \pm 3.30$ \\
\hline Liver weight (g) & $192.31 \pm 2.43$ & $188.13 \pm 3.26$ & $192.91 \pm 2.98$ & $192.58 \pm 2.32$ \\
\hline $\operatorname{ALT}(\mathrm{mg} / \mathrm{dl})$ & $37.16 \pm 6.76$ & $26.60 \pm 2.56$ & $27.60 \pm 3.51$ & $22.60 \pm 1.93$ \\
\hline AST (mg/dl) & $57.33 \pm 13.83$ & $73.66 \pm 6.28$ & $70.00 \pm 12.28$ & $61.40 \pm 3.66$ \\
\hline $\operatorname{ALP}(\mathrm{mg} / \mathrm{dl})$ & $148.20 \pm 7.12$ & $153.50 \pm 7.30$ & $156.50 \pm 1.04$ & $149.40 \pm 6.72$ \\
\hline LDH (mg/dl) & $435.20 \pm 71.20$ & $511.83 \pm 48.71$ & $484.00 \pm 21.53$ & $355.00 \pm 36.12$ \\
\hline Kidney weight (g) & $0.28 \pm 0.00$ & $0.26 \pm 0.01$ & $0.27 \pm 0.01$ & $0.27 \pm 0.00$ \\
\hline BUN (mg/dl) & $21.78 \pm 1.99$ & $18.72 \pm 1.49$ & $18.46 \pm 1.06$ & $19.91 \pm 0.84$ \\
\hline CRE (mg/dl) & $0.37 \pm 0.01$ & $0.32 \pm 0.01$ & $0.32 \pm 0.04$ & $0.33 \pm 0.05$ \\
\hline
\end{tabular}

The data is reported as the means \pm SD from three replicates. EtSCT, ethanol extract of $S$. clava tunics; LEtSCT, low concentration EtSCT; HEtSCT, high concentration EtSCT; ALT, alanine transaminase; AST, aspartate transaminase; ALP, alkaline phosphatase; LDH, lactate dehydrogenase; BUN, blood urea nitrogen; CRE, creatinine.

treatment with Machilus thunbergii Siebold \& Zucc. effectively reduced wrinkle formation and skin thickness on hairless mice subjected to UV radiation (40). The skin erythema index in a jujube water extract (JWE)-treated group was significantly lower than that of a control group (41), and the oral intake of sea buckthorn (Hippophae rhamnoides $\mathrm{L}$.) fruit blend (SFB) induced decreased wrinkle formation and TEWL during UV-induced skin aging (23). However, no studies have shown that the administration of SCT extracts closely correlate with the decreased formation of wrinkles, TEWL and erythema in skin, to the best of our knowledge. One possible mechanism of protection is the inhibition of tyrosinase activity, which is the rate limiting enzyme that regulates the production of melanin in skin melanocytes (42). Thus, this study is the first to suggest that the topical application of EtSCT may prevent or alleviate the formation of wrinkles, TEWL and erythema during UV-induced skin aging, to the best of our knowledge.

The epidermis contains different levels of melanin in the skin, which may play a significant role in determining photoprotective effects against underlying cells (43). Following UV radiation, the epidermal thickness and the number of adipocytes were recovered to a similar level as that in the no radiation group. However, it has been previously demonstrated that treatment with several extracts, including M. thunbergii, Artocarpus communis and SFB, resulted in a significant decrease in epidermal thickness and the number of adipocytes relative to the control $(23,40,44)$. In the present study, only epidermal thickness was rapidly decreased in all EtSCT-treated groups (Fig. 2 and Table III). These findings are similar to those of a previous study in which a decrease in epidermal thickness was shown to be related to treatment with antioxidant extracts (45).

Collagen I and III, which are abundant in the dermis, polymerize to produce extended mechanically stiff fibrils, which impart tensile strength to the tissue $(46,47)$. Thus, wrinkle formation is closely correlated with the regulation of collagen synthesis and degradation (48). The majority of reports have shown that the level and distribution of collagen in the skin increases significantly following treatment with antioxidants, although this level is decreased after exposure to UV radiation $(23,49,50)$. Conversely, an opposite tendency in collagen I expression was detected in the levels of MMP-1. Specifically, MMP-1 plays important roles in the degradation of dermal collagens in the ECM composed mainly of type 1 collagen during the aging of human skin $(45,51,52)$. In this study, the collagen levels were significantly lower in the UV radiation group than in the no radiation group, but this level was markedly higher in the LEtSCT- or HEtSCT-treated groups than in the UV + vehicle-treated group. Moreover, the increase in MMP-1 expression induced by UV radiation was recovered in the HEtSCT-treated group. These changes were similar to those reported in previous studies examining the effects of tempol, retinoic acid and SFB on the collagen regulation of skin, although the variations in the increase or decrease rate differed $(23,48,49,52)$. This is the first study, to the best of our knowledge, to suggest that collagen expression may be affected by the topical application of EtSCT.

The inflammation and oxidative stress induced by ROS overproduction following exposure to UV radiation may be prevented or decreased by treatment with traditional medicines (53), natural products (45) and some powerful antioxidants such as anthocyanins and quercetin $(54,55)$.Previous studies have shown that the levels of pro-inflammatory cytokines, including IL-1 $\beta$, IL-6, IL-8 and TNF- $\alpha$, were reduced by treatment with A. communis and Butea monosperma flower extract $(55,56)$. In addition, it has been demonstrated that groups treated with JWE or (-)-epigallocatechin-3-gallate (EGCG) exhibited a relatively lower infiltration of mast cells and leukocytes in the dermis or hyperdermis relative to the vehicle-treated group $(41,57)$. The present study revealed that the increase in mast cell numbers and cytokine expression induced by UV radiation was attenuated by treatment with EtSCT, with marked decreases in the infiltration of mast cells and the expression of CD31 and IL-6 being observed. These findings are similar to the results of previous studies $(41,44,56)$. Significant changes were observed in response to the LEtSCT and HEtSCT treatments. Specifically, 
HEtSCT almost completely inhibited the infiltration of mast cells and cytokine expression in the dorsal skin of hairless mice. Taken together, these findings indicate that EtSCT is a strong candidate for use as an inhibitor of inflammation.

The excessive production of ROS during chronic UV radiation may induce an imbalance between pro-oxidant production and antioxidant defense, resulting in the stimulation of oxidative DNA damage and the peroxidation of lipids and proteins in the skin (58). Treatment with M. thunbergii and A. communis extracts as well as $\alpha$-tocopherol have been shown to reduce the formation of lipid peroxides relative to the vehicle-treated group, although the extent of the decrease varied $(40,44,59)$. In the present study, lipid peroxide levels were measured in the serum and skin tissue of hairless mice following UV + EtSCT co-treatment for 13 weeks. The MDA levels in both the serum and skin of the EtSCT-treated groups were lower than those in the UV + vehicle-treated group, which is in agreement with the results of previous studies (Fig. 6).

Taken together, these results provide the first evidence to the best of our knowledge, that EtSCT contains high levels of flavonoids and phenolic compounds that may contribute to the protection and treatment of skin damaged by UV exposure. EtSCT was particularly effective at preventing alterations in skin phenotypes and histological structures as well as regulating inflammation and oxidative conditions without exerting toxicity against the liver and kidneys.

\section{Acknowledgements}

The present study was supported by a grant to Professor Dae Youn Hwang from the Korea Institute of Marine Science and Technology Promotion (no. 112088-3).

\section{References}

1. Millar RH: The identity of the ascidians Styela mammiculata Carlisle and Styela clava Herdman. J Mar Biol Assoc UK 39: 509-511, 1960

2. Carlisle DB: Styela mammiculata n.sp., a new species of ascidian from the Plymouth area. J Mar Biol Assoc UK 33: 329-334, 1954

3. Kang PA, Kim Y and Yoon DS: Studies on the hanging culture of oyster, Crassostrea gigas, in the Korean coastal waters (IV). On the fouling organisms associated with culturing oysters at the oyster culture farms in Chungmu. Bull Natl Fish Res Dev Agency 25: 29-34, 1980.

4. Davis MH and Davis ME: First record of Styela clava (Tunicata, Ascidiacea) from the Mediterranean Sea. Aquatic Invasions 3: 125-132, 2008.

5. Park JH and Suh YC: GIS-Based Suitable Site Selection for aquaculture using scope for growth of Styela clava. J Korean Assoc Geogr Inf Stud 16: 81-90, 2013.

6. Shin YK, Park JJ, Park MS, Myeong JI and Hur YB: Effect of temperature and dissolved oxygen on the survival rate and physiological response of the warty sea squirt Styela clava. Korean J Environ Biol 32: 216-224, 2014.

7. Ahn SH, Jung SH, Kang SJ, Jeong TS and Choi BD: Extraction of glycosaminoglycans from Styela clava tunic. Korean J Biotechnol Bioeng 18: 180-185, 2003.

8. Lee SM, Kang EJ, Go TH, Jeong SY, Park GT, Lee HS, Hwang DY, Jung YJ and Son HJ: Screening of biological activity of solvent extract from Styela clava tunic for fishery waste recycling. J Environ Sci Intern 23: 89-96, 2014.

9. Jung YJ: Properties of regenerated cellulose films prepared from the tunicate Styela clava. J Kor Fish Soc 41: 237-242, 2008.

10. Jung YJ, An BJ, Hwang DY, Kim HD, Park SM, Cho H and Kim HS: Preparation and properties of regenerated cellulosic biomaterial made from Styela clava tunics. Biomater Res 12: 71-76, 2008.
11. Kwak MH, Go J, Kim JE, Lee YJ, Lee SH, Lee HS, Son HJ, Jung YJ and Hwang DY: Property and efficacy analysis of hydrocolloid membrane containing Styela clava Tunic on the wound repair of skin in SD rats. Biomater Res 17: 91-101, 2013.

12. Kim SM, Lee JH, Cho JA, Lee SC and Lee SK: Development of a bioactive cellulose membrane from sea squirt skin for bone regeneration - A preliminary research. J Korean Assoc Oral Maxillofac Surg 31: 440-453, 2005.

13. Xu CX, Jin H, Chung YS, Shin JY, Woo MA, Lee KH, Palmos GN, Choi BD and Cho MH: Chondroitin sulfate extracted from the Styela clava tunic suppresses TNF- $\alpha$-induced expression of inflammatory factors, VCAM-1 and iNOS by blocking Akt/NF-kappaB signal in JB6 cells. Cancer Lett 264: 93-100, 2008

14. Nacional LM, Kang SJ and Choi BD: Antioxidative activity of carotenoids in mideodeok Styela clava. Fish Aquat Sci 14: 243-249, 2011.

15. Song SH, Kim JE, Lee YJ, Kwak MH, Sung GY, Kwon SH, Son HJ, Lee HS, Jung YJ and Hwang DY: Cellulose film regenerated from Styela clava tunics have biodegradability, toxicity and biocompatibility in the skin of SD rats. J Mater Sci Mater Med 25: 1519-1530, 2014.

16. Singleton VL and Rossi JA: Colorimetry of total phenolics with phosphomolybdic-phosphotungstic acid reagents. Am J Enol Vitic 16: 144-158, 1965.

17. Zhishen J, Mengcheng T and Jianming W: The determination of flavonoid contents in mulberry and their scavenging effects on superoxide radicals. Food Chem 64: 555-559, 1999.

18. Oh H, Ko EK, Kim DH, Jang KK, Park SE, Lee HS and Kim YC: Secoiridoid glucosides with free radical scavenging activity from the leaves of Syringa dilatata. Phytother Res 17: 417-419, 2003.

19. Oyaizu M: Studies on products of the browning reaction. Antioxidative activities of browning reaction products prepared from glucosamine. Jpn J Nutr 44: 307-315, 1986.

20. Marcocci L, Maguire JJ, Droy-Lefaix MT and Packer L: The nitric oxide-scavenging properties of Ginkgo biloba extract EGb 761. Biochem Biophys Res Commun 201: 748-755, 1994.

21. Park CH, Lee MJ, Kim JP, Yoo ID and Chung JH: Prevention of UV radiation-induced premature skin aging in hairless mice by the novel compound Melanocin A. Photochem Photobiol 82: 574-578, 2006.

22. Nam SH, Jung SE, Lee YK, Kim JE, Lee EP, Choi HW, Kim HS, Lee JH, Jung YJ, Lee CY, et al: Topical application of selenium can significantly relieve UV-induced skin aging in hairless mice. Lab Anim Res 26: 37-45, 2010.

23. Hwang IS, Kim JE, Choi SI, Lee HR, Lee YJ, Jang MJ, Son HJ, Lee $\mathrm{HS}, \mathrm{Oh} \mathrm{CH}, \mathrm{Kim} \mathrm{BH}$, et al: UV radiation-induced skin aging in hairless mice is effectively prevented by oral intake of sea buckthorn (Hippophae rhamnoides L.) fruit blend for 6 weeks through MMP suppression and increase of SOD activity. Int J Mol Med 30: 392-400, 2012.

24. Bissett DL, Hannon DP and Orr TV: An animal model of solar-aged skin: histological, physical, and visible changes in UV-irradiated hairless mouse skin. Photochem Photobiol 46: 367-78, 1987.

25. Baba H, Masuyama A, Yoshimura C, Aoyama Y, Takano T and Ohki K: Oral intake of Lactobacillus helveticus-fermented milk whey decreased transepidermal water loss and prevented the onset of sodium dodecylsulfate-induced dermatitis in mice. Biosci Biotechnol Biochem 74: 18-23, 2010.

26. Kim HJ, Kim J, Kim SJ, Lee SH, Park YS, Park BK, Kim BS, Kim SK, Cho SD, Jung JW, et al: Anti-inflammatory effect of quercetin on picryl chloride-induced contact dermatitis in BALB/c mice. Lab Anim Res 26: 7-13, 2010.

27. Koshiishi I, Horikoshi E, Mitani H and Imanari T: Quantitative alterations of hyaluronan and dermatan sulfate in the hairless mouse dorsal skin exposed to chronic UV irradiation. Biochim Biophys Acta 1428: 327-333, 1999.

28. Philips N, Burchill D, O'Donoghue D, Keller T and Gonzalez S: Identification of benzene metabolites in dermal fibroblasts as nonphenolic: regulation of cell viability, apoptosis, lipid peroxidation and expression of matrix metalloproteinase 1 and elastin by benzene metabolites. Skin Pharmacol Physiol 17: 147-152, 2004.

29. Philips N, Conte J, Chen YJ, Natrajan P, Taw M, Keller T, Givant J, Tuason M, Dulaj L, Leonardi D and Gonzalez S: Beneficial regulation of matrix metalloproteinases and their inhibitors, fibrillar collagens and transforming growth factor- $\beta$ by Polypodium leucotomos, directly or in dermal fibroblasts, ultraviolet radiated fibroblasts, and melanoma cells. Arch Dermatol Res 301: 487-495, 2009. 
30. Yaar $M$ and Gilchrest BA: Photoageing: mechanism, prevention and therapy. Br J Dermatol 157: 874-887, 2007.

31. Langton AK, Sherratt MJ, Griffiths CEM and Watson REB: A new wrinkle on old skin: the role of elastic fibres in skin ageing. Int J Cosmet Sci 32: 330-339, 2010.

32. Sumiyoshi $M$ and Kimura Y: Effects of a turmeric extract (Curcuma longa) on chronic ultraviolet B irradiation-induced skin damage in melanin-possessing hairless mice. Phytomedicine 16 : 1137-1143, 2009

33. Jung ES, Park E and Lee SC: Antioxidant activities of extracts from parts of styela clava. J Kor Soc Food Sci Nutr 37: 1674-1678, 2008

34. Kim JJ, Kim SJ, Kim SH, Park HR and Lee SC: Antioxidant and anticancer activities of extracts from Styela plicata. J Korean Soc Food Sci Nutr 34: 937-941, 2005.

35. Kim JJ, Kim SJ, Kim SH, Park HR and Lee SC: Antioxidant and anticancer activities of extracts from Styela clava according to the processing methods and solvents. J Kor Soc Food Nutr 35 278-283, 2006

36. Park JW, You DH, Bae MS, Kim JM, Lee JH, Kim SJ, Jeon YJ, Park EJ and Lee SC: Antioxidant and antihypertensive activities of Styela plicata according to harvesting time and size. Korean Soc Food Sci Nutr 40: 350-356, 2010.

37. Yoysungnoen P, Wirachwong P, Changtam C, Suksamrarn A and Patumraj S: Anti-cancer and anti-angiogenic effects of curcumin and tetrahydrocurcumin on implanted hepatocellular carcinoma in nude mice. World J Gastroenterol 14: 2003-2009, 2008.

38. Münzel T, Gori T, Bruno RM and Taddei S: Is oxidative stress a therapeutic target in cardiovascular disease? Eur Heart J 31: $2741-2748,2010$

39. Roginsky V and Alegria AE: Oxidation of tea extracts and tea catechins by molecular oxygen. J Agric Food Chem 53: 4529-4535, 2005.

40. Uhm YK, Jung KH, Bu HJ, Jung MY, Lee MH, Lee S, Lee S, Kim HK and Yim SV: Effects of Machilus thunbergii Sieb et Zucc on UV-induced photoaging in hairless mice. Phytother Res 24: 1339-1346, 2010.

41. Choi SY and Kim YC: Alleviative effects of jujube water extract on the inflammation and barrier damage in hairless mice skin. Environ Health Toxicol 24: 351-357, 2009.

42. Iozumi K, Hoganson GE, Pennella R, Everett MA and Fuller BB Role of tyrosinase as the determinant of pigmentation in cultured human melanocytes. J Invest Dermatol 100: 806-11, 1993.

43. Yamaguchi Y, Takahashi K, Zmudzka BZ, Kornhauser A, Miller SA, Tadokoro T, Berens W, Beer JZ and Hearing VJ: Human skin responses to UV radiation: pigment in the upper epidermis protects against DNA damage in the lower epidermis and facilitates apoptosis. FASEB J 20: 1486-1488, 2006.

44. Lee CW, Ko HH, Chai CY, Chen WT, Lin CC and Yen FL: Effect of Artocarpus communis extract on UVB irradiation-induced oxidative stress and inflammation in hairless mice. Int $\mathbf{J}$ Mol Sci 14: 3860-3873, 2013.

45. Pinnell SR: Cutaneous photodamage, oxidative stress, and topical antioxidant protection. J Am Acad Dermatol 48: 1-19, 2003.

46. Gosline J, Lillie M, Carrington E, Guerette P, Ortlepp C and Savage K: Elastic proteins: biological roles and mechanical properties. Philos Trans R Soc Lond B Biol Sci 357: 121-132, 2002.
47. Heim AJ, Matthews WG and Koob TJ: Determination of the elastic modulus of native collagen fibrils via radial indentation. Appl Phys Lett 89: 181902-181903, 2006.

48. Chen S, Kiss I and Tramposch KM: Effects of all-trans retinoic acid on UVB-irradiated and non-irradiated hairless mouse skin. J Invest Dermatol 98: 248-254, 1992.

49. Yan SX, Hong XY, Hu Y and Liao KH: Tempol, one of nitroxides, is a novel ultraviolet-A1 radiation protector for human dermal fibroblasts. J Dermatol Sci 37: 137-143, 2005.

50. Vicentini FT, Fonseca YM, Pitol DL, Iyomasa MM, Bentley MV and Fonseca MJ: Evaluation of protective effect of a water-in-oil microemulsion incorporating quercetin against UVB-induced damage in hairless mice skin. J Pharm Pharm Sci 13: 274-285, 2010.

51. Brennan M, Bhatti H, Nerusu KC, Bhagavathula N, Kang S, Fisher GJ, Varani J and Voorhees JJ: Matrix metalloproteinase-1 is the major collagenolytic enzyme responsible for collagen damage in UV-irradiated human skin. Photochem Photobiol 78: 43-48, 2003.

52. Fisher GJ, Datta S, Wang Z, Li XY, Quan T, Chung JH, Kang S and Voorhees JJ: c-Jun-dependent inhibition of cutaneous procollagen transcription following ultraviolet irradiation is reversed by all-trans retinoic acid. J Clin Invest 106: 663-670, 2000.

53. Kang TH, Park HM, Kim YB, Kim H, Kim N, Do JH, Kang C, Cho Y and Kim SY: Effects of red ginseng extract on UVB irradiation-induced skin aging in hairless mice. J Ethnopharmacol 123: 446-451, 2009.

54. Tsoyi K, Park HB, Kim YM, Chung JI, Shin SC, Lee WS, Seo HG, Lee JH, Chang KC and Kim HJ: Anthocyanins from black soybean seed coats inhibit UVB-induced inflammatory cylooxygenase-2 gene expression and PGE2 production through regulation of the nuclear factor-kappaB and phosphatidylinositol 3-kinase/Akt pathway. J Agric Food Chem 56: 8969-8974, 2008.

55. Casagrande R, Georgetti SR, Verri WA Jr, Dorta DJ, dos Santos AC and Fonseca MJ: Protective effect of topical formulations containing quercetin against UVB-induced oxidative stress in hairless mice. J Photochem Photobiol B 84: 21-27, 2006

56. Krolikiewicz-Renimel I, Michel T, Destandau E, Reddy M, André P, Elfakir C and Pichon C: Protective effect of a Butea monosperma (Lam.) Taub. flowers extract against skin inflammation: antioxidant, anti-inflammatory and matrix metalloproteinases inhibitory activities. J Ethnopharmacol 148: 537-543, 2013.

57. Katiyar SK and Mukhtar H: Green tea polyphenol (-)-epigallocatechin-3-gallate treatment to mouse skin prevents UVB-induced infiltration of leukocytes, depletion of antigen-presenting cells, and oxidative stress. J Leukoc Biol 69: 719-726, 2001.

58. Hanson KM and Simon JD: Epidermal trans-urocanic acid and the UV-A-induced photoaging of the skin. Proc Natl Acad Sci USA 95: 10576-10578, 1998.

59. Lopez-Torres M, Thiele JJ, Shindo Y, Han D and Packer L: Topical application of alpha-tocopherol modulates the antioxidant network and diminishes ultraviolet-induced oxidative damage in murine skin. Br J Dermatol 138: 207-215, 1998. 